\title{
DIFERENÇA E IGUALDADE NAS RELAÇÕES DE GÊNERO: REVISITANDO O DEBATE
}

\author{
Maria de Fátima Araújo*
}

\section{RESUMO}

Este artigo retoma o histórico debate sobre a diferença e a igualdade e as mudanças ocorridas nas relaçôes de gênero sob o impacto do feminismo, da crise da masculinidade e demais transformações econômicas, sociais e culturais em curso. Toma como referência os estudos de gênero que buscam compreender os processos de produção de novas formas de subjetividade masculina e feminina, distanciadas dos tradicionais estereótipos de gênero. Conclui que tais mudanças apontam para a possibilidade concreta da construção de relaçôes de gênero mais democráticas, ideal perseguido desde a modernidade, no casamento e na família, em que o direito à igualdade e o respeito à diferença são as pedras angulares.

Palavras-chave: diferença, igualdade, relaçôes de gênero

\section{AbSTRACT}

\section{DIFFERENCE AND EQUALITY IN GENDER RELATIONS: REVISITING THE DEBATE}

This paper discusses the historical debate on difference and equality and on the changes undergone by gender relations under the impact of feminism, of the masculinity crisis and of the other economic, cultural and social changes currently underway. It is based on gender studies which seek to understand the processes of production of new forms of male and female subjectivities which are distant from the traditional gender stereotypes. The paper concludes that these changes point at the concrete possibility of building more democratic gender relations, an ideal which has been pursued since the beginning of the modern era for marriage and family, and whose cornerstones are the right to equality and the respect of difference.

Keywords: difference, equality, gender relations

* Doutora em Psicologia Social pela USP/SP; Professora da Universidade Estadual Paulista/ UNESP; Coordenadora do Grupo de Pesquisa "Violência e Relações de Gênero" (CNPq). 
Dizer que as diferenças de gênero são construçōes sociais não é nenhuma novidade. Há muito tempo o tema da "diferença sexual" é objeto de estudo das ciências sociais e da antropologia. A novidade não está na colocação da temática, mas na perspectiva de análise inaugurada pelas teóricas feministas, ou seja, uma perspectiva crítica que aponta para novas formas de interrogar e priorizar a questão da diferença e da igualdade não só entre homens e mulheres, mas entre mulheres e entre homens, categorias que não são em si universais. Essa nova vertente analítica abre uma possibilidade radical para pensar, simultaneamente, a diferença e a igualdade na sua universalidade e singularidade. Permite resgatar o processo de transformação das relaçōes de gênero, apontando para as diferentes expressōes da masculinidade e da feminilidade.

\section{O USO DE “GÊNERO” COMO CATEGORIA DE ANÁLISE}

O termo "gênero", na sua acepção gramatical, designa indivíduos de sexos diferentes (masculino/feminino) ou coisas sexuadas, mas, na forma como vem sendo usado, nas últimas décadas, pela literatura feminista, adquiriu outras características: enfatiza a noção de cultura, situa-se na esfera social, diferentemente do conceito de "sexo", que se situa no plano biológico, e assume um caráter intrinsecamente relacional do feminino e do masculino. Segundo a historiadora Joan Scott (1995), as feministas americanas começaram a usar o conceito de gênero para se referir à organização social entre os sexos e só mais tarde passaram a usá-lo para enfatizar o caráter fundamentalmente social das distinçôes fundadas sobre sexo e rejeitar o determinismo biológico implícito nos termos "sexo" ou "diferença sexual" . A introdução do caráter relacional do gênero levou a uma revisão dos estudos centrados nas mulheres e apontou para a necessidade de estudos sobre as relaçôes de gênero, uma vez que a história das mulheres não pode ser vista separada da história dos homens. O mundo das mulheres faz parte do mundo dos homens, não são esferas separadas. Tomá-los como esferas separadas reforça o mito de que a experiência de um sexo tem muito pouco ou nada a ver com o outro sexo. Além disso, acrescenta Scott (1995), o uso do termo "gênero" para designar relaçôes sociais entre os sexos rejeita radicalmente explicações biológicas que encontram um denominador comum para diversas formas de subordinação feminina. Para Scott,

O termo "gênero" torna-se, antes, uma maneira de indicar "construçōes culturais" - a criação inteiramente social de idéias sobre papéis adequados aos homens e às mulheres. Trata-se de uma forma de se referir às origens exclusivamente sociais das identidades subjetivas de homens e de mulheres. "Gênero" é, 
segundo essa definição, uma categoria social imposta sobre um corpo sexuado. Com a proliferação dos estudos sobre sexo e sexualidade, "gênero" tornou-se uma palavra particularmente útil, pois oferece um meio de distinguir a prática sexual dos papéis sexuais atribuídos às mulheres e aos homens (Scott, 1995: 75).

Na definição de Scott (1995), gênero é um elemento constitutivo das relações sociais fundadas sobre as diferenças percebidas entre os sexos e também um modo primordial de dar significado às relaçôes de poder. Para ela, essas duas proposiçôes estão intrinsecamente relacionadas. As mudanças na organização das relações sociais correspondem sempre a mudanças nas representações de poder, mas a direção da mudança não segue necessariamente um único sentido. Embora gênero não seja o único campo no qual o poder se articula, ele parece ter constituído um meio persistente e recorrente de dar eficácia à significação do poder no Ocidente, nas tradições judaico-cristã e islâmicas.

Essa leitura de Scott (1995) encontra apoio em Pierre Bourdieu (1995), para quem a di-visão do mundo, fundada sobre as diferenças biológicas, aquelas que se referem à divisão sexual do trabalho, da procriação e da reprodução, opera como a mais fundada das ilusões coletivas. Estabelecidas como um conjunto objetivo de referências, as representações de gênero estruturam a percepção e a organização concreta e simbólica de toda a vida social. Na medida em que essas referências estabelecem distribuições de poder (um controle ou um acesso diferencial às fontes materiais e simbólicas), o gênero torna-se envolvido na concepção e na construção do poder em si mesmo.

Scott (1995) historiciza o conceito de gênero e busca encontrar as maneiras pelas quais o mesmo legitima e constrói as relações sociais. Na sua concepção, esse é o primeiro passo para compreender a natureza recíproca do gênero e da sociedade e as maneiras particulares e situadas dentro de contextos específicos, pelos quais a política constrói o gênero e o gênero constrói a política. A política é um dos domínios nos quais o gênero pode ser utilizado para a análise histórica.

O uso de gênero como categoria de análise surgiu como algo renovador nos estudos feministas, mas, na prática, há algumas tensões na sua aplicabilidade. Há divergências entre os autores na utilização do conceito. A principal delas refere-se ao estatuto cognitivo do conceito. Questiona-se, com base em diferentes premissas, se gênero é uma categoria empírica ou se é, antes, uma categoria analítica.

Scott (1995), no seu artigo "Gênero: uma categoria útil de análise histórica", defende o uso do conceito como uma categoria histórica e instrumento metodológico. Baseada na observação da organização social de gênero, ela operacionaliza 
gênero como uma categoria analítica, não descrevendo os componentes de um instrumental metodológico abstratamente construído, mas de um fenômeno histórico, substrato empírico do seu conceito de gênero. Nesse artigo, a autora critica o caráter descritivo dos estudos sobre a história das mulheres, como também o uso de gênero como substituto de "mulheres", e propõe o uso do conceito, tal como o define, como um potente instrumento metodológico e teórico, politicamente útil para ultrapassar a simples descrição da história das mulheres.

Outra defensora do uso de gênero como categoria analítica é a historiadora francesa Louise Tilly (1994). Assim como Scott (1995), ela critica o caráter excessivamente descritivo dos estudos sobre a história das mulheres e defende a necessidade de se tomar o gênero como uma verdadeira categoria de análise, através de uma conceitualização que possa questionar os conceitos dominantes da disciplina histórica.

Já a antropóloga britânica Marilyn Strathern (1988) recusa o estatuto analítico do gênero. Para ela, gênero é apenas um meio de aglutinar, em uma determinada sociedade, o modo como se organizam as práticas e as idéias em torno dos sexos e dos objetos sexuados. Portanto, é uma categoria empírica, que assinala uma descontinuidade entre corpos, objetos, eventos etc de uma determinada ordem simbólica particular.

Para a socióloga brasileira Heleieth Saffiotti (1997), gênero, assim como raça/ etnia e classe, não são apenas categorias de análise. Antes de serem concebidos como constructos intelectuais, operam na realidade empírica enquanto categorias históricas. Concordando com as proposições de Scott (1995), Tilly (1994) e Saffiotti (1997), entendemos que gênero é uma categoria empírica e histórica e, como tal, pode ser usado como uma categoria analítica. Apreendido da realidade empírica, ele expressa as relações históricas e as formas de existência da realidade social.

\section{IGUALDADE E DIFERENÇA}

Além de categoria histórica, o conceito de gênero pode ser empregado também como uma categoria política para analisar a questão da igualdade e da diferença, apontando para uma nova perspectiva de interpretação e transformação da realidade social.

A questão da diferença entre os seres humanos é parte da história da humanidade. Está presente nos mais diversos discursos - filosófico, religioso, biológico/científico, psicológico, antropológico e social. Mas é na modernidade que esse tema ganha maior relevância como objeto de análise. 
Segundo Pierucci (1990), a certeza de que os seres humanos não são iguais, porque não nascem iguais e como tal não podem ser tratados como iguais, quem primeiro apregoou foi a direita, mais exatamente a ultradireita do final do século XVIII e primeiras décadas do século XIX, como reação ao ideal de igualdade e fraternidade cultuados pela Revolução Francesa. Portanto, a bandeira da defesa das diferenças, hoje empunhada à esquerda pelos "novos" movimentos sociais (das mulheres, dos negros, dos homossexuais etc), foi na origem - e permanece fundamentalmente - o grande signo das direitas, velhas ou novas, extremas ou moderadas. Funcionando no registro da evidência, as diferenças explicam as desigualdades de fato e reclamam a desigualdade (legítima) de direito.

Ao tematizar o "direito à diferença", esses movimentos sociais propõem novos imperativos categóricos para o "respeito às diferenças", a "preservação das particularidades culturais", a "irredutibilidade das experiências de gênero" e assim por diante. Para Pierucci (1990), essas reivindicaçōes do "direito à diferença" trazem em si mesmas uma grande cilada ${ }^{2}$ por sua ambigüidade, uma vez que, por mais de duzentos anos, o amor à diferença foi alimentado pelo pensamento ultraconservador.

Ao longo da história, o debate da diferença entre os sexos desenvolveu-se principalmente entre duas perspectivas: a essencialista e a culturalista. $\mathrm{O}$ discurso essencialista exalta a "diferença sexual" e defende a existência de uma "essência feminina”. Psicologizando ou biologizando as constatações sociológicas e culturais historicamente produzidas, realizam afirmaçôes universalistas que aprisionam a feminilidade em modelos estruturados, ainda que ideologicamente valorizados (mulher como mãe e esposa). Supõe um feminismo universal e acaba justificando a discriminação das mulheres em função da essência feminina. Na perspectiva culturalista, as diferenças sexuais provêm da socialização e da cultura. Sob esta ótica, a superação da ordem e das leis patriarcais eliminaria as diferenças sexuais.

Uma terceira perspectiva, desenvolvida pela feminista francesa Françoise Collin (1992), a partir do conceito de pluralidade de Hannah Arendt, reúne os conceitos antagônicos de igualdade e diferença na constituição de uma categoria que não só respeita as diferenças como necessita delas. Collin propõe pensar a diferença em três níveis: entre o sujeito-mulher e a sua condição de mulher; entre as mulheres; e entre as mulheres e o mundo dos homens. Com relação à diferença entre o sujeito mulher e a sua condição de mulher, lembra que uma mulher não é só uma mulher. Um sujeito mulher não se reduz à sua feminilidade; ao contrário, é um sujeito heterogêneo. Sobre a diferença entre as mulheres, aponta para a necessidade de construir um novo tipo de sociabilidade entre elas, que incorpore e 
articule as diferenças. Com relação às diferenças entre as mulheres e o mundo dos homens, ressalta a necessidade de uma nova forma de compreensão dessa relação.

Para Collin (1992), a diferença sexual não é uma questão teórica, mas sim uma questão da práxis. A diferença sexual só aparece na experiência do diálogo que confronta uma mulher e um homem, mulheres e homens, um sujeito-mulher (ou homem) e a sua condição de gênero, no espaço público, social ou privado. A proposta de Collin incorpora, em um diálogo contínuo, a igualdade e as diferenças sem negá-las, num constante jogo dialético em que a pluralidade e o diálogo são os princípios fundamentais.

A desconstrução da oposição binária igualdade/diferença também é defendida por Scott (1988), à luz de Derrida. Segundo ela, a própria antítese igualdadeversus-diferença oculta a interdependência dos dois termos, uma vez que a igualdade não é a eliminação da diferença e a diferença não impede a igualdade. Desconstruída essa antítese, diz Scott, será possível não só dizer que os seres humanos nascem iguais mas diferentes, como também sustentar que a igualdade reside na diferença. Para a autora, o uso do discurso da diferença macho-fêmea envolve uma outra cilada: oculta as diferenças entre as mulheres (e entre homens), no comportamento, no caráter, no desejo, na subjetividade, na sexualidade, na identificação de gênero e na experiência histórica. Há uma enorme diversidade de identidades de mulheres e homens, que supera essa classificação masculino/feminino; a categoria macho/fêmea suprime as diferenças dentro de cada categoria. A única alternativa é, pois, recusar a oposição igualdade/diferença e insistir continuamente nas diferenças como a condição das identidades individuais e coletivas, como o verdadeiro sentido da própria identidade. Na proposta desconstrucionista de Scott, a diferença binária daria lugar à diferença múltipla, única forma de fugir das armadilhas da disjunção igualdade ou diferença.

\section{A LUTA FEMINISTA PELA IGUALDADE NA DIFERENÇA}

No início do movimento feminista, a luta pela igualdade se sobrepôs à questão da diferença. Foi somente na segunda metade da década de 70 e no decorrer dos anos 80 que o debate sobre a igualdade-versus-diferença tornou-se o centro das discussōes. Atribuindo à diferença uma valência positiva, as feministas direcionaram sua luta em prol da igualdade na diferença. Passou-se então a falar de diferença cultural, cultura feminina, experiência feminina, reconhecimento da diversidade cultural de gênero e assim por diante.

$\mathrm{Na}$ análise de Oliveira (1993), em Elogio da diferença, o feminismo transgrediu a ordem que atribuía ao masculino o direito de definir o feminino como 
seu avesso. A idéia da igualdade entre os sexos foi o primeiro estágio dessa transgressão. As mulheres tentaram ultrapassar as fronteiras do mundo dos homens, mas "na luta pela igualdade tropeçaram na diferença" (p. 72). Durante muito tempo, a diferença foi usada como sinônimo de desigualdade dentro da hierarquia imposta pela dominação masculina. Mas a luta pela igualdade já nasceu capenga, diz Oliveira, uma vez que as mulheres se esforçavam para assimilar os modelos masculinos. Elas queriam ocupar os espaços dos homens, comportandose, agindo, sentindo e falando como eles. E, assim, acabaram se defrontando com uma crise de identidade, ao perceberem que com esses comportamentos supervalorizavam as qualidades consideradas masculinas, em detrimento das femininas, denotando um forte sentimento de inferioridade internalizado. Isso trouxe muita ambigüidade às mulheres e resultou em um grande "mal-estar", que levou a uma revisão do feminino.

Revistas as estratégias de luta, no final dos anos 80 , as mulheres passaram a defender a igualdade não mais em nome da capacidade de se assemelharem aos homens, mas, sobretudo, pelo direito de ser diferentes deles. "O feminismo da diferença, desdobramento do feminismo da igualdade, introduziu um questionamento mais radical, trazendo a promessa de uma contribuição sociocultural inédita e subversiva" (Oliveira, 1993: 73).

Para Oliveira (1993), os valores são o fundamento da diferença. As mulheres são diferentes dos homens, porque no centro de sua existência estão outros valores: a ênfase no relacionamento interpessoal, a atenção e o cuidado com o outro, a proteção da vida, a valorização da intimidade e do afetivo, a gratuidade das relações. A identidade feminina provém da interação com os outros. Daí serem as mulheres mais intuitivas, sensíveis e empáticas. Daí também vem o terrível sentimento de divisão em que mergulham, quando, no percurso de acesso ao espaço público, se vêem obrigadas a confrontar seu modo de ser com as exigências de sucesso no mundo dos homens, marcado por agressividade, competitividade, objetividade e eficiência.

No nosso entender, a análise de Oliveira (1993) retrata o grande nó do discurso feminista: ao levantar a bandeira da igualdade na diferença e propor uma valorização do feminino, acaba caindo no velho dualismo feminismo/masculino, atribuindo valores e características diferentes para cada sexo. Quando se universalizam essas diferenças, obscurecem-se outras possibilidades de homens e mulheres se diferenciarem dos modelos rígidos e estereotipados. Muitas das características atribuídas ao masculino e ao feminino não são determinadas apenas pelo gênero, são influenciadas também pela classe social, pela cultura, pela educação, bem como por características individuais de personalidade - nem todos os homens são agres- 
sivos, objetivos, seguros de si etc, da mesma forma que nem todas mulheres são inseguras, pouco agressivas e sem objetividade.

Não obstante, a grande conquista do projeto feminista igualdade na diferença foi a possibilidade de mudança nas relações de gênero, na medida em que as mulheres (e os homens) puderam se libertar dos velhos estereótipos e construir novas formas de se relacionar, agir e se comportar. Essa possibilidade tem permitido aos homens se libertarem do peso do machismo e às mulheres se libertarem do imperativo do feminino, ambos podendo ser sensíveis, objetivos, fortes, inseguros, dependentes, independentes, com liberdade e autonomia, e não seguirem imperativos categóricos determinados pelo gênero. É assim que se concretiza a idéia de gênero como construção social. Nessa perspectiva, a reconstrução do feminino leva necessariamente à reconstrução do masculino. Essa relação nunca será uma relação sem conflito; ao contrário, será sempre um espaço de luta e tensão dialética, onde estão em jogo diferentes poderes e desejos. Por isso, é importante que homens e mulheres, nas suas experiências subjetivas, possam exercitar a lógica, a razão, a intuição e a sensibilidade para construir novos valores e novas formas de se relacionar na vida afetivo-sexual, no casamento , na família, no trabalho, enfim, em todas as relaçôes sociais.

\section{A CRISE DA MASCULINIDADE E AS NOVAS RELAÇŌES DE GÊNERO}

As mudanças provocadas pelo feminismo desestabilizaram o modelo masculino tradicional e colocaram a necessidade de sua revisão. Desde a década de 70, a questão masculina tem sido objeto de muitos estudos, em diferentes países, como Estados Unidos, Canadá, França, Brasil, Peru (Tolson, 1977; Carrigan, Connel \& Lee, 1985; Bly, 1991; Badinter, 1993; Nolasco, 1993, Fuller, 1997). Tendo como preocupação básica "repensar o masculino" e compreender os processos de mudança por que passam os homens, tais estudos adotam em suas análises a perspectiva social e/ou relacional de gênero. Como diz Badinter: "longe de ser pensada como absoluta, a masculinidade, atributo do homem, é relativa e reativa. Tanto que, quando a feminilidade muda - em geral, quando as mulheres querem redefinir sua identidade - a masculinidade se desestabiliza" (Badinter, 1993: 11). Repensar o masculino supõe rever modelos de comportamentos, teorias e discursos que, ao longo da história, têm sido usados para explicar a masculinidade (Connel, 1995), Nolasco (1995), Jablonski (1995), Fuller (1997), Oliveira (1998), Welzer-Lang (2001).

A discussão sobre a questão masculina retoma caminhos semelhantes aos percorridos pelo feminismo. Polariza-se entre os determinismos biológico e social 
e questiona a idéia de uma masculinidade universal. Apóia-se em estudos da antropologia social e cultural, que confirmam a existência de uma multiplicidade de masculinidades, conforme observou Mead (1971) em diferentes culturas.

A crise da masculinidade ganhou mais evidência nos últimos anos, mas ela tem precedentes nos séculos XVII e XVIII, na Inglaterra e na França. Nesses dois países, onde a educação era mais refinada, as mulheres gozavam de mais liberdade que em outros lugares. Segundo Badinter (1993), foram as "preciosas francesas" quem primeiro questionaram a identidade masculina e o papel dos homens na sociedade, e seus questionamentos tiveram grande repercussão.

Consideradas as primeiras feministas, as "preciosas" - mulheres da aristocracia e alta burguesia, solteiras, independentes economicamente-, defendiam a igualdade entre os sexos, o direito ao amor e ao prazer sexual, o acesso à mesma educação intelectual dada aos homens. Questionando a instituição casamento e os papéis de esposa e mãe como destino da mulher, elas inverteram os valores sociais da época. Apesar de seus opositores, elas conseguiram algumas mudanças (Badinter, 1993: 12).

O apogeu do "preciosismo" francês ocorreu por volta de 1650 e 1660. Na Inglaterra, segundo Kimel (1987, citado por Badinter, 1993), a verdadeira crise da masculinidade ocorreu entre 1688 e 1714, época em que houve muitos esforços de negociação dos papéis do homem e da mulher no casamento, na família e na sexualidade. Tudo isso ganhou corpo com a idéia do amor romântico que se gestava, na preocupação com a felicidade, no desenvolvimento do individualismo e outras mudanças radicais que surgiam com a modernidade.

Contraditoriamente, a Revolução Francesa acabou com essa evolução. Negou às mulheres o direito de cidadãs e retomou a tradicional separação entre os sexos, que durou por mais de 100 anos. Só no século XX o movimento de mulheres voltou a ganhar força na luta pelo direito ao voto, à cultura e à educação, à igualdade nas condições de trabalho, enfim, lutando pela igualdade em todas as instâncias antes dominadas pelos homens. Mas é na década de 60, sob a égide do feminismo, que a luta das mulheres ganha visibilidade e se fortalece como um movimento social responsável por mudanças radicais nos valores, nos costumes, nas relações de trabalho e na família.

Portanto, pode-se dizer que o movimento das mulheres, assim como o movimento dos homens, é resultado das condições históricas decorrentes das grandes transformações sociais, econômicas e culturais iniciadas no século XVII. O capitalismo, na sua evolução, enfraqueceu o patriarcado e, à medida que o poder 
paterno declinava, as mulheres foram ocupando espaço na esfera pública, tanto para atender às necessidades do mercado de trabalho quanto da própria família, uma vez que o homem já não dava conta do seu papel de provedor. Com a necessidade de trabalhar - seja para complementar a renda familiar, seja por realização pessoal -, a mulher se defronta com novas questôes, como o controle contraceptivo diante da decisão de ter ou não filhos, e a necessidade de dividir tarefas e responsabilidades, na esfera doméstica. Conseqüentemente, todas essas questôes tiveram implicações na vida dos homens. O que não quer dizer, como lembra Nolasco (1993), que a transição vivida pelos homens seja simplesmente decorrência do movimento das mulheres, uma vez que o movimento dos homens tem características próprias. A mudança das mulheres e a mudança dos homens expressam a crise do individualismo vivenciada como crise do sentimento de identidade. Nolasco insiste em separar o movimento das mulheres do movimento dos homens. Para ele, a crise de identidade dos homens se inicia com a crise do mundo do trabalho e da família e não com o feminismo. No nosso entender, essas questôes não são excludentes, ambos os movimentos são decorrência de um processo de transformação mais amplo, iniciado com a ascensão do capitalismo na Europa, que levou a enormes mudanças nos valores dominantes no mundo do trabalho, na família e nas relações afetivo-sexuais.

Como resultado dessas transformações, pode-se observar, nos últimos anos, o crescimento do número de homens que buscam formas alternativas de subjetividade distanciadas do modelos sexistas. Segundo Nolasco (1993), nessa trajetória reflexiva os homens estão tomando consciência das tensões e conflitos impostos pelo machismo e descobrindo a possibilidade de, livres dos grilhôes estereotipados, reconhecer as suas reais necessidades afetivas e buscar meios de satisfazê-las sem se sentirem menos "machos" por isso. E, assim, podem descobrir o prazer de amar e se relacionar de outra forma, em que a abertura para intimidade, a troca afetiva e o contato com os sentimentos são experiências valorizadas.

Concluindo, pode-se dizer que, nos dias de hoje, pelo menos nas sociedades ocidentais, homens e mulheres estão se distanciando dos modelos estereotipados de gênero e desenvolvendo novas formas de subjetividade, livres do imperativo das divisões traçadas pelas representações sociais até então vigentes. A idéia de que existe um modelo masculino ou feminino universal não se sustenta mais. Sob a égide da pluralidade e da singularidade, surgem diferentes modos de ser da masculinidade e da feminilidade que convivem, de forma já não tão conflituosa, com as matrizes hegemônicas de gênero ainda existentes. Neste cenário, conforme já apontamos em outro estudo (Araújo, 1999), abre-se a possibilidade concreta de construir relações de gênero mais democráticas, nas quais o direito à igualdade e o 
respeito à diferença são as pedras angulares. Não é demais afirmar que esse continua sendo o ideal de relacionamento perseguido no casamento e na família desde a modernidade.

\section{REFERÊNCIAS BIBLIOGRÁFICAS}

Araújo, M. F. (1999). Casamento e sexualidade. A revisão dos mitos na perspectiva de gênero. Tese de Doutorado. Programa de Pós-Graduação em Psicologia Social. Universidade de São Paulo, São Paulo.

Badinter, E. (1992/1993). XY - Sobre a identidade masculina (M. I. D. Estrada, Trad.). Rio de Janeiro: Nova Fronteira.

Bly, R. (1991). João de Ferro. Rio de Janeiro: Campus.

Bourdieu, P. (1995). A dominação masculina. Educação \& Realidade, 20 (2), 133-184.

Carrigan, T; Connel, B. \& Lee, J. (1985). Toward a new sociology of masculinity. Em Theory and Society, 14 (5), 551-603.

Collin, F. (1992). Práxis de la différence. Paris: Les Cahiers du Grief.

Connel, R. W. (1995). Políticas de masculinidade. Educação \& Realidade, 20 (2), 185206.

Fuller, N. (1997). Identidades masculinas. Lima: Fondo Editorial de la Pontificia Universidad Católica del Perú.

Jablonski, B. (1995). A difícil extinção do boçalossauro. Em Nolasco, S. (Org.). A desconstrução do masculino (pp. 156-165). Rio de Janeiro: Rocco.

Mead, M. (1949). Macho e fêmea. (M. M. Moura, Trad.). Rio de Janeiro: Vozes, 1971.

Nolasco, S. (1993). O mito da masculinidade. Rio de Janeiro: Rocco.

- (1995). A desconstrução do masculino: uma contribuição crítica à análise de gênero. Em Nolasco, S. (Org.). A desconstrução do masculino (pp. 15-29). Rio de Janeiro: Rocco.

Oliveira, R. D. (1993). Elogio da diferença. O feminino emergente. São Paulo: Brasiliense.

Oliveira, P. P. (1998). Discursos sobre a masculinidade. Estudos Feministas, 6 (1), 91-112.

Pierucci, A. F. (1990). Ciladas da diferença. Tempo Social, 2 (2), 7-33.

Saffiotti, H. I. B. (1992). Rearticulando gênero e classe social. Em Costa, A. O. \& Bruschini, C. (Org.). Uma questão de gênero (pp. 183-215). Rio de Janeiro: Rosa dos Tempos.

- (1997). Influências do pós-modernismo nas teorias feministas. Trabalho apresentado no XXI Congresso da ALAS/Associação Latino-Americana de Sociologia. São Paulo. Scott, J. (1988). Gender and the politics of history. New York: Columbia University Press. . (1995). Gênero: uma categoria útil de análise histórica. Educação \& Realidade, 20 (2), 71-99. 
Strathern, M. (1988). The gender of the gift. California: Berkeley University of California Press.

Tilly, L. A. (1994). Gênero, história das mulheres e história social. Cadernos Pagu, 3, 2962.

Tolson, A. (1977). Os limites da masculinidade. Lisboa: Assírio Alvim.

Welzer-Lang, D. (2001). A construção do masculino: dominação das mulheres e homofobia. Estudos Feministas, 9 (2), 460-481.

\section{NoTAS}

1 É importante assinalar que existe outra postura, que recusa a utilização do conceito de gênero. Michele Ferrand (1989), em extenso levantamento da literatura feminista francesa, verificou o amplo uso do conceito relaçôes sociais de sexo. Para muitas feministas francesas, o próprio sexo não se inscreve puramente no terreno biológico, mas sofre uma elaboração social, que não se pode negligenciar sob pena de naturalizar processos históricos (cf. Saffiotti, 1992: 183).

2 O uso ideológico da diferença, lembra Pierucci (1990), pode ser visto no Caso Sears, ocorrido nos Estados Unidos em 1979, quando a Equal Employment Opportunities Comission (EEOC), do governo americano, moveu um processo criminal contra a Sears por discriminação sexual em sua política de contratação de pessoal. O julgamento teve como protagonistas duas feministas: Alice Kessler, responsável pela acusação com base no direito à igualdade, e Rosalind Rosenberg, responsável pela defesa com base no direito à diferença. Sobre o Caso Sears, ver Milkman. R. Women's (1986) History and the Sears Case. Feminist Studies. New York, 12 (2), 375-400.

Recebido 20 de dezembro de 2004 Aceito para publicação em 29 de março de 2005 